\title{
POWER FACTOR IMPROVEMENT OF INVERTER USING DFACTS
}

\author{
Miss.Supriya S.Kadam \\ Department of Electronics Engineering \\ Shivaji University, Kolhapur, Maharashtra, India
}

\begin{abstract}
Improvement in Power Factor (PF) is vital issue in power electronics field. For three phase inverter, Distributed Flexible Alternating Current Transmission System (DFACTS) devices are used with grid connections. DFACTS devices helps to enhance the active power level whereas with reduction in Reactive power level. To maintain the power factor approximately one, it is necessary to control reactive power at Inverter. This paper represents MATLAB simulation of Grid connected Inverter using DFACTS devices for power factor improvement. Power factor is improving with the help of DFACTS devices for grid connected inverter.
\end{abstract}

Keywords-Power Factor, Inverter, FACTS, DFACTS

\section{INTRODUCTION}

Power system supplies electric energy to customers. In the last few decades the extensive growth of industries results into tremendous demand of electrical energy. The demand for large amount of power increases the burden on the electrical energy generation station. Generation station is supposed to provide electrical energy to the distribution system and finally reached to consumers. All consumer products need electrical energy with higher power quality for larger life span. But, the difficulty lies in the maintenance of the electrical power quality [1]-[7].

There are many disadvantages of poor and low power quality. It may lead to higher power losses, abnormal and unusual behavior of electrical equipment, and interference with the nearby communication lines, poor voltage profile, harmonics, sag and swells in the voltage, poor and low distortion and displacement factor. Consumer equipments are more sensitive to variation of power quality and power quality is load sensitive [8]-[12].

The fundamental problem is the non-sinusoidal current of inverters and ripple in the rectifiers that contain the fundamental as well as higher order harmonic components. The displacement and distortion factors also become poor as these devices draw leading

\author{
Dr.Yuvraj K.Kanse \\ Department of Electronics Engineering \\ K.B.P.C.O.E., Satara, Maharashtra, India
}

or lagging and non-sinusoidal current from the supply, thereby resulting in the injection of harmonics in the distribution systems [13]. The harmonic current then starts flowing across the line and source impedance and this causes distortion of voltages, excessive power loss and voltage drop. Malfunctioning of protection, control, and the metering equipment occurs as the power supply gets distorted [14].

Hence, Power system needs for the compensation of higher power quality. Many consumers are also there whose need of power quality is high than what provided by the electrical networks. So it's very much essential to obtain a higher quality of electrical power [15].

Flexible Alternating Current Transmission System (FACTS) devices are used widely in order to compensate higher power quality. In order to assure a high and better power quality, custom power devices and Flexible Alternating Current Transmission System (FACTS) devices are used widely. Distributed Flexible Alternating Current Transmission System (FACTS) devices are an alternative solution to solve the main problem of the last generation of Flexible Alternating Current Transmission System (FACTS) devices. It offers a higher performance and lower cost method for enhancing smart or micro grids controllability and reliability. This system provides many potential benefits since they are less expensive and smaller than usual Flexible Alternating Current Transmission System (FACTS) devices [16]-[27]. Some of the features of Distributed Flexible Alternating Current Transmission System (DFACTS) devices are cost effective power flow control, dynamic control of the effective line impedance, to address power control types of problems, enhancing asset utilization and end-user power quality, etc[28]-[30].

\section{PROPOSED WORK}

Power quality is the vital problem in the field of electrical energy generation, transmission and utilization. Power quality should maintain at its best possible higher level during generation, transmission 


\section{International Journal of Engineering Applied Sciences and Technology, 2019 \\ Vol. 4, Issue 5, ISSN No. 2455-2143, Pages 315-318 \\ Published Online September 2019 in IJEAST (http://www.ijeast.com)}

and utilization. Recent development of the smart grid and micro-grid supports decentralization of power generation and power is distributed with possible higher power quality [1]-[16]. Smart grid emerged as an efficient way of generating, distribution and utilization of electric energy. Renewable energy sources connected to the smart grid through grid connected inverters. These inverters have more impact on the power quality, as the inverter introduces harmonics in the power supply. The cost effective power flow control is the main problem of the last generation of Flexible Alternating Current Transmission System (FACTS) devices. The problem is overcome by improving power quality for grid connected inverter using Distributed Flexible Alternating Current System devices. To solve different problems in smart or micro grids such as voltage sags, voltage swells, voltage fluctuations, interruptions and harmonics, various power conversions, Distributed Flexible Alternating Current Transmission System (DFACTS) devices is widely used[17]-[20].

The original motivation behind the research into power quality improvement of grid connected inverter was increasing use of Renewable Energy Sources as Distributed Generator in the electrical distribution network application. Nowadays, the entire electrical industry sectors is transforming into modern electrical networks due to increasing performance and decreasing price of power electronics and communication technologies. Currently, deployment of low power Flexible Alternating Current Transmission System (FACTS) devices, i.e. Distributed Flexible Alternating Current Transmission System (D-FACTS) are designed to address power control types of problems [20]-[30].

The proposed system consists of signal conditioning circuit, system controller and control parameters, switching controller, inverter, D-FACTS devices and load. The signal conditioning system may be voltage and current sensing or detection system along with signal conversion unit. The system controller is used to control the different tasks of the grid connected inverter based on the different conditions. The switching controller controls the switching actions of power devices of inverter.

The grid connected inverter using D-FACTS devices is deployed. The Parameter samples are taken into consideration for the analysis of the grid connected inverter performance. The performance of grid connected inverter regarding power quality is based on the control algorithm process by system controller. Switching actions of power devices of grid connected inverter is decided by switching controller operated by system controller. The control parameters are assumed to be ideal for power quality improvement of grid connected inverter

Distributed Flexible Alternating Current Transmission System (D-FACTS) devices for Grid connected inverter provide the power factor improvement, minimization of harmonics and voltage stability, Where intelligent power quality monitoring and improvement can be achieved via the usage of Distributed FACTS, controller and control algorithm along with embedded devices.

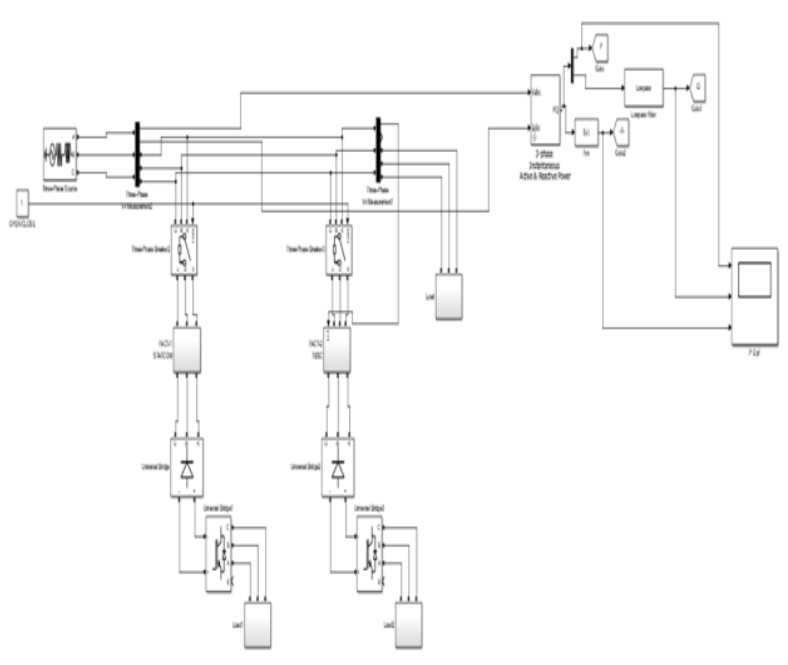

Fig. 1. MATLAB Simulink model for Proposed work

Fig.1. shows the MATLAB Simulink model for proposed work. Inverter is connected along with DFACTS devices such as DSSC (Distributed Static Series Compensator), DSTATCOM (Distributed Synchronized Static Compensator). These two devices are used to control flow of power such as active \& reactive power.

\section{RESULTS AND DISCUSSION}

DFACTS devices such as DSTATCOM \& DSSC are used to control the power factor. Both Distributed FACTS devices are used to control the voltage flickers, voltage sags \& swell, frequency variations, phase difference. Power factor is controlling using both DFACTS devices.

Without using D-FACTS devices, power factor is 0.8 shown in fig.2. Active power increases and reactive power is also varies, so that power factor is 0.8 . In open loop, DFACTS devices are disconnected from the Inverter. So, effect of controlling the power flow is vanishing. Now, there is variation in active \& reactive power.

DFCATS devices such as DSTATCOM \& DSSC are used here for the purpose of control the active $\&$ reactive power flow. Along with the power flow control, these devices also maintain rate of voltage $\&$ current fluctuations. 
International Journal of Engineering Applied Sciences and Technology, 2019

Vol. 4, Issue 5, ISSN No. 2455-2143, Pages 315-318

Published Online September 2019 in IJEAST (http://www.ijeast.com)

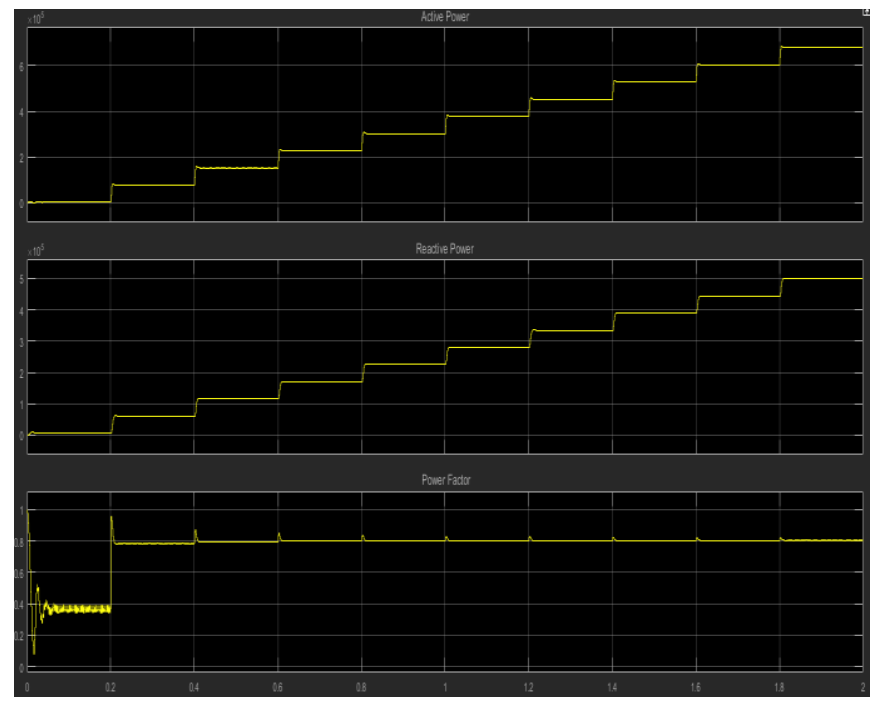

Fig. 2. Power factor for Open Loop

Fig.3.shows Power Factor for Close Loop. In Close Loop, Active power is increasing because of DFACTS devices which are connected across the inverter. DFACTS Devices helps to control the fluctuations in active power and reduces the reactive power. With the use of DFACTS devices, the power factor is improved upto 0.99 i.e. approximatly 1. So, the effect of these devices is observed on Power Factor. Power factor is approximatly one.

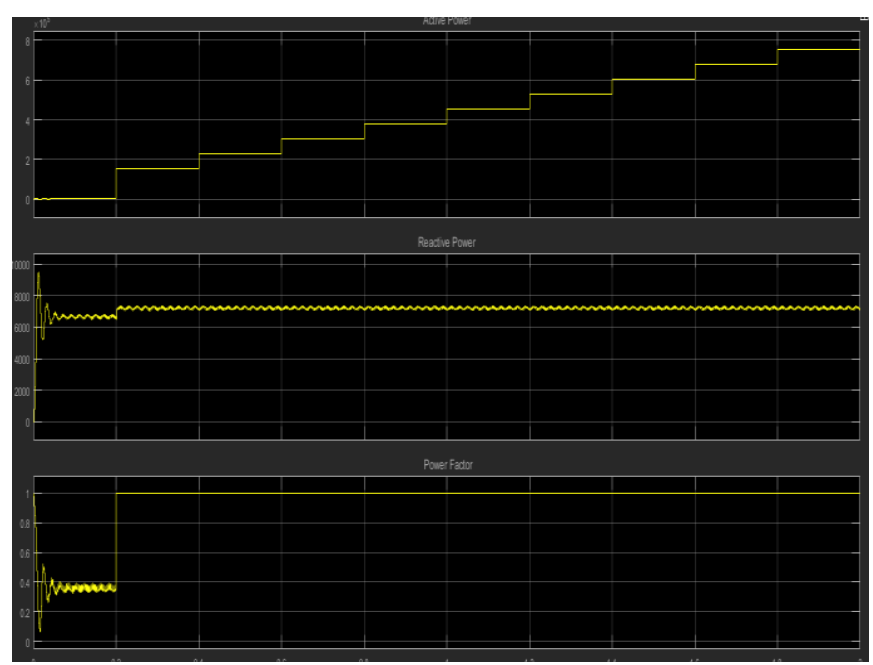

Fig. 3. Power factor for Close Loop

Table 1 shows the values of Power factor, Active power and Reactive power for both open loop \& close loop. It is observed that without DFACTS devices power factor is less as compared to with DFACTS devices i.e. close loop.

For open loop, Reactive power is more as compared to Active power. For close loop, Active power is more as compared to reactive power.
Table -1 Experimentation Result

\begin{tabular}{|c|c|c|c|}
\hline $\begin{array}{c}\text { Sr. } \\
\text { No. }\end{array}$ & Specification & Open Loop & Close Loop \\
\hline 1 & Power Factor & 0.8 & 0.99 \\
\hline 2 & Active Power & 498.851 KW & 752.298 KW \\
\hline 3 & Reactive Power & $677.433 \mathrm{KW}$ & $7.163 \mathrm{KW}$ \\
\hline
\end{tabular}

\section{CONCLUSION}

Power flow control is done by the DFACTS devices which are connected across grid connected Inverter. These devices is used to control power flow, THD, Voltage fluctuations. Distributed FACTS devices are used for power factor improvement. Using DFACTS devices, active power flow is increased with reduction in reactive power. Power factor is 0.8 for open loop \& 0.99 for close loop. Active power is $498.851 \mathrm{KW}$ for open loop \& $752.298 \mathrm{KW}$ for close loop. Reactive power is $677.433 \mathrm{KW}$ for open loop \& 7.163 KW for close loop. Reactive power is minimized by using DFACTS devices.

\section{REFERENCE}

[1]. Bin Liu ; Mei Su ; Jian Yang ; Dongran Song; Deqiang He; Shaojian Song , "Combined Reactive Power Injection Modulation and Grid Current Distortion Improvement Approach for H6 Transformer-Less Photovoltaic Inverter" , IEEE Transactions on Energy Conversion, Volume: 32 , Issue: 4 , Dec. 2017, pp. 1456 - 1467

[2]. Tsai-Fu Wu, Chh-Lung Shen; Chien-Hsuan Chang; Jeiyang Chiu, "1/spl phi/ 3W gridconnection PV power inverter with partial active power filter", IEEE Transactions on Aerospace and Electronic Systems, Volume: 39, Issue: 2, April 2003, pp. $635-646$

[3]. Sandeep Madishetti ; Bhim Singh; Gurumoorthy Bhuvaneswari, "Three-Level NPC-Inverter-Based SVM-VCIMD With Feedforward Active PFC Rectifier for Enhanced AC Mains Power Quality”, IEEE Transactions on Industry Applications ( Volume: 52 , Issue: 2, March-April 2016 )pp. $1865-1873$

[4]. Francisco J. Azcondo; F. Javier Diaz; Christian Branas ; Rosario Casanueva, "Microcontroller Power Mode Stabilized Power Factor Correction Stage for High Intensity Discharge Lamp Electronic Ballast", IEEE Transactions on Power Electronics, Volume: 22 , Issue: 3 , May 2007,pp. $845-853$

[5]. Vashist Bist ; Bhim Singh, "A Unity Power Factor Bridgeless Isolated Cuk Converter-Fed Brushless DC Motor Drive", IEEE Transactions on Industrial Electronics, Volume: 62 , Issue: 7 , July 2015 , pp. $4118-4129$ 


\section{International Journal of Engineering Applied Sciences and Technology, 2019 \\ Vol. 4, Issue 5, ISSN No. 2455-2143, Pages 315-318 \\ Published Online September 2019 in IJEAST (http://www.ijeast.com)}

[6]. Xiaolong Chen; Yongli Li , "An Islanding Detection Algorithm for Inverter-Based Distributed Generation Based on Reactive Power Control", IEEE Transactions on Power Electronics, Volume: 29 , Issue: 9 , Sept. 2014, pp. $4672-4683$

[7]. C.J. Hatziadoniu ; F.E. Chalkiadakis ; V.K. Feiste ," A power conditioner for a grid-connected photovoltaic generator based on the 3-level inverter", IEEE Transactions on Energy Conversion, Volume: 14, Issue: 4 , Dec 1999, pp. $1605-1610$.

[8]. Chandana Jayampathi Gajanayake ; D. Mahinda Vilathgamuwa; Poh Chiang Loh; Remus Teodorescu ," Z-Source-Inverter-Based Flexible Distributed Generation System Solution for Grid Power Quality Improvement", IEEE Transactions on Energy Conversion, Volume: 24 , Issue: 3 , Sept. 2009, pp. $695-704$

[9]. Chandan Kumar ; Mahesh K. Mishra , "A VoltageControlled DSTATCOM for Power-Quality Improvement", IEEE Transactions on Power Delivery, Volume: 29 , Issue: 3 , June 2014, pp. $1499-1507$

[10]. Dipendra Rai ; Sherif O. Faried; G. Ramakrishna ; Abdel-Aty Edris , "An SSSC-Based Hybrid Series Compensation Scheme Capable of Damping Subsynchronous Resonance", IEEE Transactions on Power Delivery, Volume: 27 , Issue: 2 , April 2012 , pp. 531 - 540.

[11]. Mohammadreza Dorostkar-Ghamsari ; Mahmud Fotuhi-Firuzabad ; Farrokh Aminifar, "Probabilistic Worth Assessment of Distributed Static Series Compensators", IEEE Transactions on Power Delivery, Volume: 26, Issue: 3 , July 2011 , pp. $1734-1743$

[12]. Li Wang; Quang-Son Vo , "Power Flow Control and Stability Improvement of Connecting an Offshore Wind Farm to a One-Machine InfiniteBus System Using a Static Synchronous Series Compensator" , IEEE Transactions on Sustainable Energy,Volume: 4, Issue: 2, April 2013, pp. $358-369$.

[13]. Tomas Hornik ; Qing-Chang Zhong, "A CurrentControl Strategy for Voltage-Source Inverters in Microgrids Based onHळand Repetitive Control”, IEEE Transactions on Power Electronics, Year: 2011 , Volume: 26, Issue: 3,Pages: 943 - 952.

[14]. Amardeep $\quad$ B. Shitole ; Hiralal M. Suryawanshi; Girish G. Talapur; Shelas Sathyan; Makarand S. Ballal; Vijay B. Borghate; Manoj R. Ramteke; Madhuri A. Chaudhari, “ Grid Interfaced Distributed Generation System With Modified Current Control Loop Using Adaptive Synchronization Technique”, IEEE Transactions on Industrial Informatics, Year: 2017 , Volume: 13 , Issue: 5,Pages: $2634-2644$.

[15]. C.J. Hatziadoniu ; F.E. Chalkiadakis ; V.K. Feiste, " A power conditioner for a grid- connected photovoltaic generator based on the 3 levelinverter", IEEE Transactions on Energy Conversion, Year: 1999 , Volume: 14, Issue: 4, Pages: $1605-1610$ 